\title{
Percepção dos alunos de ciências contábeis sobre a prática da contabilidade aplicada ao terceiro setor
}

\author{
Ana Paula Nascimento da Silva \\ Universidade Federal do Rio Grande do Norte - UFRN \\ Brasil \\ Maria Aparecida do Nascimento Cavalcanti Marques \\ Universidade Federal Rural do Rio de Janeiro - UFRRJ \\ Brasil \\ Roberto Silva da Penha \\ Universidade Federal de Minas Gerais - UFMG \\ Brasil
}

Data da submissão:20/12/2017

Data de aceite:28/08/2018

\begin{abstract}
RESUMO
O presente trabalho tem como objetivo verificar a percepção dos alunos de graduação dos cursos de ciências contábeis da grande Natal e de Mossoró sobre a prática da contabilidade aplicada ao terceiro setor. Esta pesquisa se caracteriza como descritiva, com auxílio de uma pesquisa bibliográfica, utilizando para a coleta de dados um questionário aplicado em seis instituições de ensino superior (IES) de Natal e uma de Mossoró para traçar um perfil dos estudantes de contabilidade acerca do tema terceiro setor. Os resultados da pesquisa levaram a concluir que os alunos de contabilidade das IES analisadas possuem pouco conhecimento sobre o assunto, o que demonstra que elas estão deixando falhas no que diz respeito ao cumprimento do conteúdo programático sugerido para o ensino da disciplina.
\end{abstract}

Palavras-chave: Terceiro setor. Contabilidade. Ensino.

\begin{abstract}
The present work has the objective of verifying the perception of undergraduate students of the courses of accounting sciences of the great Natal and Mossoró on the practice of accounting applied to the third sector. This research is characterized as descriptive, with aid of a bibliographical research, using for data collection a questionnaire applied to six higher education institutions (HEIs) in Natal and one in Mossoró to draw a profile of accounting students about third sector subject. The results of the research led to the conclusion that the accounting students of the HEIs analyzed have little knowledge about the subject, which shows that they are failing to comply with the programmatic content suggested for teaching the discipline.
\end{abstract}

Keywords: Third sector. Accounting. Teaching.

\section{INTRODUÇÃO}

A estrutura econômica da sociedade está dividida em três setores. O primeiro setor é constituído pelo governo, cuja finalidade é oferecer à população os serviços básicos importantes 
para a manutenção da sociedade. O segundo setor refere-se ao mercado, o qual é representado pelas entidades privadas com finalidade de geração de lucros. E o terceiro setor é composto por entidades privadas, mas que não possuem finalidade lucrativa e que realizam ações de caráter público, tendo como objetivo promover o bem-estar social.

Para Fagundes et al. (2012), o terceiro setor é uma derivação dos outros dois setores, pois ele é composto por organizações que visam beneficiar a coletividade, mas ao mesmo tempo não pertencem ao governo, sendo de natureza privada, embora não objetivem auferir lucros.

Segundo Falconer (1999), a emergência do terceiro setor no Brasil representa uma mudança de direção no que diz respeito ao papel do Estado e do mercado, particularmente na participação do cidadão na esfera pública, pois veio para suprir as lacunas deixadas pelas ações do primeiro e do segundo setor, uma que vez que busca soluções para atender às necessidades da sociedade e reduzir as desigualdades sociais e econômicas.

De acordo com dados divulgados pelo Instituto Brasileiro de Geografia e Estatística (IBGE), no estudo realizado sobre as fundações privadas e associações sem fins lucrativos no Brasil em 2005, o número dessas organizações aumentou 22,6\% entre os anos de 2002 e 2005. Essa expansão apresentou desaceleração, conforme dados das últimas pesquisas, na qual apresentou aumento de 8,8\% no número de organizações do terceiro setor (BRASIL, 2012).

Apesar da desaceleração no crescimento do setor, ele tem uma representação expressiva, prova disso é o quanto do produto interno bruto (PIB) esse setor representa. Segundo Merege (2007), em 2006, quando passou a compor o cálculo do PIB, o setor representava aproximadamente $1,5 \%$ do total da riqueza gerada pelo país.

Diante da sua importância, o terceiro setor tem provocado uma série de preocupações em relação às suas práticas gerenciais. E cabe à contabilidade, enquanto ciência social, tornar as informações confiáveis, trazendo para a gestão dessas instituições a transparência na prestação de contas. Isto se faz necessário, para que sejam evidenciados aos seus stakeholders a origem dos recursos e como esses recursos foram aplicados para benefício da sociedade.

Para que a contabilidade possa auxiliar na gestão dessas entidades, é necessário que as instituições de ensino superior (IES) possam formar profissionais capazes de atender a essa demanda do mercado, sobretudo ao que se refere às normas e procedimentos contábeis específicos das organizações de interesse social.

De acordo com dados divulgados pelo IBGE , o terceiro setor aumentou sua participação na economia e, juntamente com o seu crescimento, aumentou também o número de pessoal ocupado e assalariado do setor, em que os trabalhadores possuíam, em média, uma renda mensal 
equivalente a 3,3 salários mínimos, além de ter um aumento expressivo do número de trabalhadores com nível superior de escolaridade no setor (BRASIL, 2012).

Assim como as instituições pertencentes aos setores público e privado, as entidades do terceiro setor também necessitam de informações que possam ser relevantes para a tomada de decisão, pois elas possuem o dever de gerar informações que possam ser usadas para a prestação de contas à sociedade e que possam ser importantes instrumentos de transparência para uma boa gestão dos seus recursos.

A contabilidade possui um papel importante na geração de informações, sendo necessário que os profissionais que chegam ao mercado possam estar preparados para suprir essas necessidades, e as IES têm o papel de formar não somente profissionais qualificados, mas também formar cidadãos que possam atuar nesse campo.

Diante destes pontos, justifica-se a presente pesquisa com a seguinte questão-problema: Qual a percepção dos alunos de graduação dos cursos de ciências contábeis da grande Natal e de Mossoró sobre a prática da contabilidade aplicada ao terceiro setor? O objetivo é verificar a percepção dos alunos de ciências contábeis da grande Natal e de Mossoró sobre as práticas contábeis aplicadas ao terceiro setor.

Os resultados desta pesquisa podem proporcionar aos professores e coordenadores de cursos de contabilidade adaptar o conteúdo do tema terceiro setor a fim de alcançar uma maior eficiência no processo de ensino-aprendizagem, e permitir que outras pesquisas possam ser feitas a partir da estrutura deste trabalho.

\section{FUNDAMENTAÇÃO TEÓRICA}

Esta seção aborda uma visão mais ampla do que é o terceiro setor e logo após apresenta a contabilidade e o ensino no terceiro setor.

\subsection{Terceiro setor}

Para Olak e Nascimento (2010), buscar uma definição para o terceiro setor não é nada fácil, uma vez que a expressão sem fins lucrativos é usada para designar as entidades fora do contexto do estado e do mercado, e não reflete o que são e qual o seu papel no contexto econômico e social.

Muitos são os termos utilizados para designar esse tipo de organização no Brasil, que tem como característica promover ações de natureza privada com fins públicos. Alguns exemplos são: organizações não governamentais (ONGs), organizações sem fins lucrativos, organizações voluntárias, setor independente, terceiro setor. 
Diversos autores (COELHO, 2000; PAES, 2003; OLAK; NASCIMENTO, 2010; BOSSARD II, 2013; OLAK; SLOMSKI; ALVES, 2008) têm discutido esse assunto, a fim de que consigam chegar a uma definição unificadora englobando as suas características comuns dessas organizações.

Para Coelho (2000), essa variedade de denominações mostra que há uma falta de precisão conceitual para designar o setor, o que mostra a dificuldade de enquadrar toda a diversidade das organizações em um padrão comum.

Conforme Paes (2003), o terceiro setor é composto por um conjunto de organismos, organizações ou instituições sem finalidade de lucros dotados de autonomia e que possuem como objetivo atuar na sociedade em busca de seu aperfeiçoamento.

Segundo Rosa (2003), o terceiro setor é a junção entre as finalidades do primeiro setor e a metodologia do segundo, composto por organizações que visam benefícios à coletividade e são de natureza privada, embora não possuam como objetivo auferir lucros. Desta forma, as organizações sem finalidade lucrativa buscam atender às demandas da sociedade, uma vez que o governo não tem como supri-las, gerando, assim, benefícios para a coletividade.

Segundo Bossard II (2013), o terceiro setor mobiliza um grande volume de recursos humanos e materiais para impulsionar iniciativas voltadas para o desenvolvimento social e, com isso, suprir as lacunas de uma ação ineficiente do primeiro setor e de um segundo setor voltado para a cumulação de riquezas.

As entidades pertencentes ao terceiro setor possuem um papel de grande importância para a sociedade, uma vez que seu objetivo é desenvolver ações que visam promover o bemestar mediante ações de natureza beneficente. Para isso, utiliza-se de recursos oriundos de contribuições, doações ou de convênios realizados em parceria com o primeiro setor.

Olak, Slomski e Alves (2008), enfatizam que as organizações privadas sem finalidade lucrativa vêm desenvolvendo ações cada dia mais abrangentes na sociedade, com atividades de cunho beneficente, filantrópico, caritativo, religioso, cultural, educacional, científico, artístico, literário, recreativo, de proteção ao meio ambiente, esportivo, entre outros, tudo em prol do bem comum.

Olak e Nascimento (2010) definem as instituições sem fins lucrativos como instituições privadas que possuem propósitos específicos de provocar mudanças na sociedade, sendo seu patrimônio constituído, mantido e ampliado por meio das contribuições, doações e subvenções e jamais pode ser revertido para seus mantenedores ou membros.

As entidades sem finalidade lucrativa não são aquelas que não obtêm rendimento, ao contrário, elas podem gerar recursos por meio de suas atividades, mas essa característica se dá 
pelo fato de que todo o superávit apurado não é distribuído aos seus membros e sim utilizado para a manutenção das atividades da própria instituição.

Outra característica importante das entidades pertencentes ao terceiro setor é que elas gozam de benefícios concedidos pelo governo para o desenvolvimento de suas atividades, quais sejam: imunidade e isenção de alguns tributos.

Desta forma, as entidades que gozem dos benefícios da imunidade e da isenção devem reconhecer, para cada tributo, a despesa e o passivo como sendo devidos, para, então, reconhecer a receita baixando o passivo correspondente. Os convênios devem ser contabilizados conforme o Pronunciamento Técnico $\mathrm{n}^{\circ} 07$ do Comitê de Pronunciamentos Contábeis (CPC, 2010) e a receita devidamente reconhecida.

As entidades sem fins lucrativos são financiadas por recursos próprios, doações, subvenções, financiamentos, sendo na maioria das vezes pelo capital privado, como é o exemplo das fundações, cujo patrimônio advém de doações de um instituidor em vida ou depois de sua morte, quando manifestada essa vontade em testamento. Mas elas também são financiadas por recursos públicos.

Como esse tipo de organização não possui finalidade lucrativa, todo superávit apurado deve ser reinvestido na própria instituição, uma vez que ele não pode ser distribuído entre os detentores do patrimônio da sociedade e garante que ela continue e desempenhar suas atividades.

\subsection{Contabilidade e o ensino no terceiro setor}

Marion (2009) define a contabilidade como sendo um instrumento importante para a tomada de decisões, e informa que da mesma maneira que as organizações privadas se beneficiam dessas informações, as organizações do terceiro setor utilizam essa ferramenta para atingir seu objetivo, que é o bem-estar da sociedade.

Para Iudícibus (2010), a contabilidade precisa ser um sistema capaz de produzir informações em certo intervalo de tempo que possam ser relevantes para os seus usuários, de modo que não sejam esgotadas as necessidades deles, mas que sirvam de apoio imediato para uma tomada de decisão importante.

A partir do crescimento apresentado pelo setor nos últimos anos, de acordo os dados divulgados pelo IBGE (BRASIL, 2012), torna-se necessário que essas entidades possam dar maior enfoque à sua prestação de contas. Em virtude disso, a contabilidade ganhou maior importância como ferramenta necessária para a transparência na gestão dos recursos. 
Percepção dos alunos de ciências contábeis sobre a prática da contabilidade aplicada ao terceiro setor

Niyama e Silva (2011) falam que a contabilidade deve mostrar preocupação com o trabalho das organizações do terceiro setor, principalmente no desenvolver de seu objetivo de ajudar os menos favorecidos, além de ser um importante instrumento de gestão na prestação de contas aos seus doadores dos recursos aplicados.

Os usuários das informações contábeis são divididos em externos e internos, os usuários externos são representados pelas instituições bancárias, fornecedores, governos, pessoas físicas etc., já os usuários internos são os administradores, diretores, funcionários, entre outros, e todos possuem interesses diferentes nas informações geradas pela contabilidade, de modo que as elas precisam ser fidedignas e mostrar a real situação patrimonial da entidade.

Existe uma legislação específica para a contabilidade das entidades sem fins lucrativos, criada pela Fundação Brasileira de Contabilidade (FBC, 2012), que é o Caderno de Procedimentos Aplicáveis à Prestação de Contas das Entidades do Terceiro Setor (Fundações), que veio para dar maior ênfase à contabilidade dessas entidades.

O ensino da contabilidade vem passando por grandes mudanças e precisa se adaptar às novas formas de ensino, aos novos conteúdos que surgem e às mudanças ocorridas no cenário nacional e internacional, como forma de preparar melhor os profissionais que saem das IES para o mercado. Para unificar esse ensino, foi criada a Proposta Nacional de Conteúdo para o Curso de Graduação em Ciências Contábeis (FBC, 2009).

Na Resolução no 10/2004, o Conselho Nacional de Educação (CNE), estabelece novas diretrizes para o ensino da contabilidade, como forma de unificar os conteúdos a serem ministrados para os alunos, para que eles sejam capazes de compreender as questões científicas, sociais, técnicas, econômicas e financeiras das organizações e apresentar domínio no desenvolver de suas funções (BRASIL, 2004).

Ainda conforme a resolução, as IES devem incluir em suas matrizes curriculares conteúdos visando a formação do caráter profissional do aluno por meio dos componentes curriculares integrantes, sistemas de avaliação, estágio curricular obrigatório, atividades complementares, monografia ou trabalho de conclusão de curso e regime de oferta, devendo incluir, se não nas disciplinas obrigatórias, pelo menos no quadro das optativas, a disciplina de Contabilidade Aplicada às Entidades de Interesse Social, como forma de complementação na formação do estudante, como sugere a Proposta Nacional de Conteúdo para o Curso de Graduação em Ciências Contábeis (FBC, 2009), em que para cada uma dessas disciplinas seja apresentada a ementa, o conteúdo programático, a bibliografia, a carga horária e os objetivos gerais. 
O ensino da contabilidade aplicada às entidades de interesse social deve seguir a Proposta Nacional de Conteúdo, de modo que o conteúdo seja ministrado de tal forma que o aluno, ao final da disciplina, possa ter conhecimento do funcionamento das entidades, sua gestão contábil, prestação de contas aos seus usuários, benefícios e obrigações e apresentação das demonstrações contábeis.

Estudos anteriores (RODRIGUES et al., 2016; ALVES; TEIXEIRA; OLIVEIRA, 2017; CAVALCANTE et al., 2017), buscaram investigar a percepção de alunos quanto à compreensão de elementos estudados na área de contabilidade.

Rodrigues et al. (2016) encontraram resultados que apontaram que houve uma percepção de qualidade de ensino razoável dos alunos quanto aos conteúdos de perícia contábil, contudo identificaram uma falta de integração dos estudantes com os profissionais do mercado. Vale salientar que esse estudo foi feito em IES da cidade de Natal - RN, com 128 respondentes.

Já o trabalho de Alves, Teixeira e Oliveira (2017), envolvendo 111 estudantes do curso de administração, avaliou a percepção desses alunos em relação às disciplinas da área contábil e identificou problemas envolvendo a complexidade do conteúdo, entretanto, percebeu um interesse deles pelas disciplinas, inclusive optativas, em virtude da potencial contribuição na gestão das organizações.

Levando em conta a percepção dos estudantes em relação ao nível de conhecimento dos discentes do curso de graduação de ciências contábeis no tocante à contabilidade ambiental, Cavalcante et al. (2017) constataram um baixo nível de conhecimento dos discentes envolvendo a temática da contabilidade ambiental, pouca aplicação dos conceitos e que esses conhecimentos podem permitir vantagem competitiva para as empresas.

\section{MÉTODO DE PESQUISA}

\subsection{Tipo de pesquisa}

Para Beuren et al. (2012), os tipos de pesquisa baseiam-se em três pontos: quanto aos objetivos, aos procedimentos e à abordagem do problema. De acordo com os autores, o que vai definir o tipo de pesquisa são os objetivos estabelecidos para o trabalho. Diante disso, esta pesquisa se caracteriza: quanto aos objetivos, como descritiva; quanto aos procedimentos, como bibliográfica e de levantamento; e em relação à abordagem, como quantitativa.

A pesquisa descritiva, segundo Andrade (2002), preocupa-se em analisar os fatos, registrar, interpretar e classificar sem que o pesquisador interfira no resultado. Para Gil (2008), a pesquisa bibliográfica é desenvolvida tomando como base material já produzido e publicado acerca do tema, principalmente livros e artigos científicos. 
Já a pesquisa de levantamento, segundo Gil (2008), caracteriza-se pelo fato de buscar respostas diretas das pessoas cujos perfis se deseja conhecer, e consiste na solicitação de informações dentro desse grupo acerca do problema estudado para, a partir das respostas, obter as conclusões correspondentes aos dados coletados, mediante uma análise quantitativa.

Para Richardson (1999), a pesquisa quantitativa se caracteriza por utilizar a quantificação tanto para a coleta de dados quanto para o tratamento das técnicas estatísticas, desde os mais simples aos mais complexos. Neste estudo, utilizou-se a pesquisa quantitativa de forma a permitir traçar um perfil dos estudantes de contabilidade acerca do ensino da contabilidade aplicada ao terceiro setor.

\subsection{População e amostra}

De acordo com Beuren et al. (2012), a população ou universo da pesquisa representa a totalidade dos elementos que possuem uma determinada paridade em relação às características definidas para um determinado estudo, enquanto a amostra é uma pequena parcela da população ou do universo selecionado.

Neste estudo, procura-se analisar a percepção dos alunos de ciências contábeis em relação à prática da contabilidade aplicada ao terceiro setor, sendo a população representada pelos alunos de ciências contábeis e a amostra definida por critérios de acessibilidade, pelos alunos matriculados nas IES localizadas em Natal e em Mossoró, cidades do estado do Rio Grande do Norte. O questionário, portanto, foi direcionado a seis IES de Natal e uma de Mossoró, que possuem o curso de ciências contábeis na modalidade presencial, resultando em 112 respondentes.

\subsection{Procedimento, coleta de dados e tratamento}

O procedimento utilizado para coleta de dados foi feito a partir da aplicação de questionários aos alunos das IES de Natal e Mossoró, matriculados nos cursos graduação em ciências contábeis do primeiro ao décimo período.

Segundo Beuren et al. (2012), um questionário é um instrumento para coleta de dados constituído por uma série ordenada de perguntas, em que elas devem ser respondidas pelo pesquisado ao pesquisador. Segundo Marconi e Lakatos (2010). os questionários devem obedecer a normas específicas para que se possa ter maior eficácia na coleta dos dados.

O questionário aplicado aos alunos foi elaborado e enviado por meio eletrônico, mediante a ferramenta do Google Docs. O link foi disponibilizado aos professores e 
coordenadores de curso para que fosse repassado aos seus alunos, ficando disponível para respostas entre os meses de fevereiro e maio de 2014.

A primeira parte do questionário inicia-se traçando um perfil dos alunos pesquisados em relação a gênero, faixa etária, IES, período em que está cursando, obrigatoriedade do ensino da disciplina e nível de conhecimento sobre o tema. A segunda parte é composta de perguntas específicas em relação à contabilidade aplicada ao terceiro setor.

Para a formulação do questionário, foi utilizado o modelo da escala de Likert, que permite que os respondentes especifiquem seu grau de concordância com uma afirmação. Segundo Marconi e Lakatos (2010), a escala de Likert é um dos métodos de escala mais simples de ser construído e o mais utilizado em questionários de pesquisa de opinião.

O questionário foi estruturado com perguntas fechadas, em que todos foram submetidos às mesmas questões e alternativas para respostas em relação ao tema abordado, sendo atribuída a cada resposta uma escala de 1 a 5, correspondendo, respectivamente, a: discordo muito, discordo pouco, indiferente, concordo pouco e concordo muito.

Para se chegar a uma melhor análise dos resultados, foi estabelecida uma média ponderada (MP) e um ranking médio (RM) das respostas. Observando-se a frequência das respostas de acordo com sua concordância ou discordância com relação às perguntas e ao número de respondentes, é possível obter a MP e o RM de pontuação atribuída às respostas, em que todos os valores menores que 3 foram considerados "discordantes", os iguais a 3 "indiferentes" e maiores que 3 concordantes, numa escala de 5 pontos.

Para o cálculo da MP e do RM, foi utilizado o método de análise baseado na escala do tipo Likert, no qual:

$$
\begin{gathered}
M P=\Sigma(f i . V i) \\
R M=M P /(N S)
\end{gathered}
$$

Em que: $f i=$ frequência observada de cada resposta para cada item; $V i=$ valor de cada resposta; e $N S=$ número de sujeitos.

Quanto mais próximo a 5 o RM estiver, maior será o seu nível de concordância do respondente, e quanto mais próximo de 1 , menor será sua discordância em relação ao tema abordado.

\section{ANÁLISE DOS RESULTADOS}


Percepção dos alunos de ciências contábeis sobre a prática da contabilidade aplicada ao terceiro setor

Da amostra constituída por seis IES localizadas no município de Natal e uma de Mossoró que dispõem do curso de ciências contábeis na modalidade presencial, obteve-se como retorno 112 questionários respondidos, os quais serão analisados a seguir.

\subsection{Características dos respondentes}

A primeira parte do questionário objetivou identificar o perfil dos respondentes, cuja função foi classifica-los e caracterizá-los de acordo com o gênero, faixa etária, IES e período em que está cursando. Além dessa caracterização, buscou-se verificar se havia obrigatoriedade da disciplina em relação à grade curricular, além de analisar o nível de conhecimento em relação ao tema proposto.

Os questionamentos acerca de gênero e faixa etária possuem como objetivo identificar como estão divididos os estudantes para então se fazer uma análise das IES nas quais estudam, e do período em que estão cursando.

A Tabela 1 mostra os resultados para a classificação dos respondentes quanto ao gênero, dos 112 estudantes que participaram da pesquisa, 56\% são representados pelo gênero feminino e $44 \%$ pelo gênero masculino.

Tabela - 1 Classificação dos respondentes conforme o gênero

\begin{tabular}{|c|c|c|c|}
\hline Gênero & Frequência & Percentual & Percentual acumulado \\
\hline Feminino & 63 & 56,0 & 56,0 \\
\hline Masculino & 49 & 44,0 & 100,0 \\
\hline Total & 112 & 100,0 & \\
\hline
\end{tabular}

Fonte: dados da pesquisa.

A Tabela 2 apresenta os resultados para a classificação dos entrevistados quanto à sua faixa etária, é possível identificar que a maioria dos estudantes se encontra na faixa entre 23 e 27 anos de idade (44\%), e uma pequena maioria entre a faixa dos 28 aos 32 anos de idade (6\%).

Tabela 2 - Classificação dos respondentes conforme a idade

\begin{tabular}{lccc}
\hline \multicolumn{1}{c}{ Idade } & Frequência & Percentual & Percentual acumulado \\
\hline Entre 18 e 22 anos & 38 & 34,0 & 34,0 \\
Entre 23 e 27 anos & 49 & 44,0 & 78,0 \\
Entre 28 e 32 anos & 07 & 6,0 & 84,0 \\
Acima de 32 anos & 18 & 16,0 & 100,0 \\
\hline Total & $\mathbf{1 1 2}$ & $\mathbf{1 0 0 , 0}$ & \\
\hline
\end{tabular}

Fonte: dados da pesquisa.

Outro ponto relevante para a pesquisa é saber em qual período do curso se encontram os respondentes, se a disciplina faz parte do quadro das disciplinas obrigatórias e também qual 
Percepção dos alunos de ciências contábeis sobre a prática da contabilidade aplicada ao terceiro setor

o nível de conhecimento desses alunos em relação à temática que está sendo discutida. A Tabela 3 apresenta a classificação de acordo com o período.

Tabela 3 - Classificação dos respondentes quanto ao período

\begin{tabular}{lccc}
\hline \multicolumn{1}{c}{ Período } & Frequência & Percentual & Percentual acumulado \\
\hline Entre o $1^{\circ}$ e $3^{\circ}$ período & 23 & 20,5 & 20,5 \\
Entre o $4^{\circ}$ e $6^{\circ}$ período & 26 & 23,2 & 43,7 \\
Entre o $7^{\circ}$ e $10^{\circ}$ período & 60 & 53,6 & 97,3 \\
Não responderam & 03 & 2,7 & 100,0 \\
\hline Total & $\mathbf{1 1 2}$ & $\mathbf{1 0 0 , 0}$ & \\
\hline
\end{tabular}

Fonte: dados da pesquisa.

A partir da análise da Tabela 3, é possível identificar que a maior parte dos respondentes, aproximadamente 53,6\% dos estudantes, já cursou mais da metade do curso. De acordo com a Proposta Nacional de Conteúdo para o Curso de Graduação em Ciências Contábeis (FBC, 2009), nesse período, grande parte dos alunos já têm concluído os conteúdos de formação básica e profissional e já está apta para as disciplinas de conteúdo optativo e que possuem uma formação complementar para o aluno.

Percebe-se que grande parte dos estudantes pesquisados está vinculada à Universidade Federal do Rio Grande do Morte (UFRN), com um total de 67\% em relação à amostra pesquisada, uma vez que representa a IES com o maior número de alunos na região pesquisada. A Universidade Federal Rural do Semi-Árido (Ufersa) e o Centro Universitário do Rio Grande do Norte (UNI-RN) apresentaram, respectivamente, um percentual de $13 \%$ e de $12 \%$ da amostra. Aproximadamente $92 \%$ dos respondentes estão vinculados a essas três IES, enquanto $1 \%$ não respondeu a qual IES está vinculado, conforme apresentado na Figura 1.

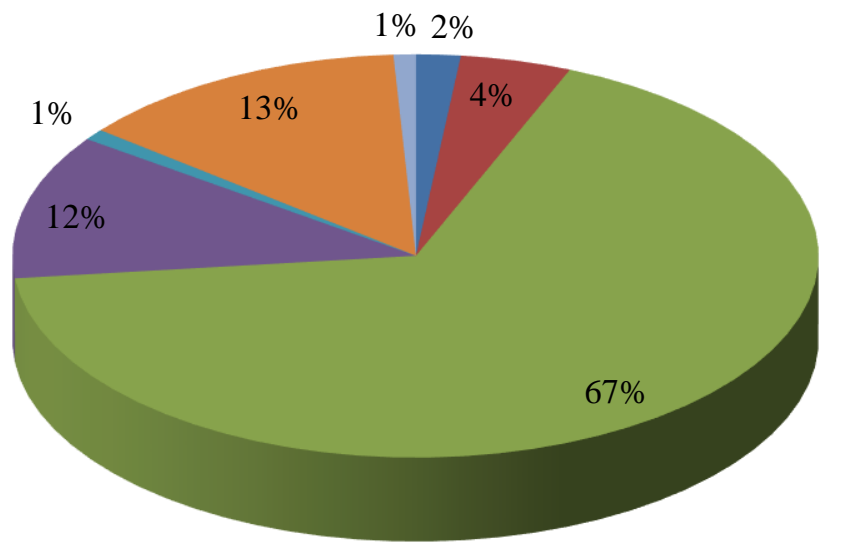

-FACEX

- FANEC

- UFRN

- UNI - RN

UNP

- UFERSA

não responderam 
Figura 1 - Classificação dos respondentes quanto ao vinculo institucional.

Fonte: dados da pesquisa.

Outro questionamento foi no que tange à obrigatoriedade do ensino da disciplina, verificou-se que $64 \%$ responderam que a disciplina é oferecida apenas como optativa nas IES às quais estão vinculados. Dos outros $36 \%$ que responderam que a disciplina é obrigatória, estão os alunos matriculados na Faculdade Natalense de Ensino e Cultura (Fanec), na Ufersa e na Universidade Potiguar (UnP).

Sendo essa disciplina ofertada no quadro das optativas, o resultado evidencia que as IES estudadas estão de acordo com o que o Conselho Nacional de Educação, por meio da Proposta Nacional de Conteúdo (FBC, 2009), sugere para os cursos de ciências contábeis no Brasil.

Na Tabela 4 é possível identificar que, do total de 112 estudantes, aproximadamente metade deles $(45 \%)$ conhece pouco sobre o terceiro setor, enquanto $24 \%$ apenas já ouviram falar, mas desconhecem as normas e procedimentos contábeis aplicados às entidades do terceiro setor. Em extremos diferentes, têm aqueles que desconhecem o assunto, com $16 \%$ do total, e aqueles que sentem confiança suficiente para falar sobre a contabilidade do terceiro setor e se dizem conhecedor das regras contábeis aplicadas e demais procedimentos, representando $15 \%$.

Tabela 4 - Nível de conhecimento sobre o assunto

\begin{tabular}{lccc}
\hline \multicolumn{1}{c}{ Nível de conhecimento sobre o assunto } & Frequência & Percentual & Percentual acumulado \\
\hline Desconheço o assunto & 18 & 16,1 & 16,1 \\
Conheço pouco sobre o assunto & 50 & 44,6 & 60,7 \\
Já ouvi falar, mas desconheço sobre os mecanismos de & & & 84,8 \\
contabilidade para o terceiro setor & 27 & 24,1 & 100,0 \\
Conheço sobre o tema contabilidade do terceiro setor & 17 & 15,2 & \\
\hline Total & $\mathbf{1 1 2}$ & $\mathbf{1 0 0 , 0}$ & \\
\hline
\end{tabular}

Fonte: dados da pesquisa.

Esse resultado sugere uma falta de conhecimento dos alunos não apenas relacionado ao tema, mas também acerca da ementa da disciplina. Além disso, percebe-se um desconhecimento sobre a Proposta Nacional dos Cursos de Ciências Contábeis (FBC, 2009), a qual propõe às IES do Brasil que adotem uma matriz curricular que atenda às constantes necessidades de atualização e inovação do mercado e, ao mesmo tempo, não fuja do conteúdo específico que deve ser ministrado obedecendo à ementa do curso.

A matriz curricular é composta das disciplinas obrigatórias e optativas, estágio curricular, trabalho de conclusão de curso e atividades complementares, sugerindo-se às IES a disciplina de Contabilidade Aplicada às Entidades de Interesse Social como optativa. 


\subsection{Percepções acerca do tema}

A segunda parte do questionário se propôs a analisar a percepção dos respondentes acerca do tema em questão. Foram elaboradas perguntas sobre a definição de terceiro setor, normas contábeis e legislação aplicadas às entidades de interesse social e procedimentos de contabilidade específicos da área.

As perguntas de 1 a 10 trouxeram afirmativas que buscaram analisar o nível de conhecimento dos estudantes sobre as práticas da contabilidade aplicada ao terceiro setor. Nas questões 1 e 3, respectivamente, os alunos foram avaliados a respeito das normas contábeis sobre apresentação das demonstrações contábeis e sobre a obrigatoriedade de as instituições do terceiro setor conservarem os documentos arquivados durante 5 anos e manterem uma contabilidade atualizada. As respostas foram analisadas tomando como base o ranking médio.

As médias foram 3,52 para a questão 1 e 4,02 para a questão 3, ou seja, elas se mantiveram mais próximas de 5 do que de 1 , o que sugere uma concordância em relação ao assunto, isto é, que os estudantes respondentes do questionário possuem algum conhecimento sobre as normas contábeis aplicadas para as entidades do terceiro setor.

O quesito 2 foi quanto ao conceito jurídico de entidades do terceiro setor. Conforme índica o Código Civil, as entidades de interesse social podem ser constituídas sob a natureza jurídica de fundação de direito privado, associação, organização social, organização religiosa, partido político e entidade sindical (BRASIL, 2002). O resultado foi satisfatório, pois a média da questão foi de 4,5, desta forma, o resultado revela que os estudantes pesquisados conhecem sobre a definição das entidades de interesse social.

Na questão 4 foi abordada a obrigatoriedade da entrega das declarações acessórias para as entidades do terceiro setor, tais como: Declaração de Informações Econômico-Fiscais das Pessoas Jurídicas (DIPJ), Demonstrativo de Apuração das Contribuições Sociais (Dacon), Declaração de Débitos e Créditos Tributários Federais (DCTF) e Relação Anual de Informações Sociais (Rais).

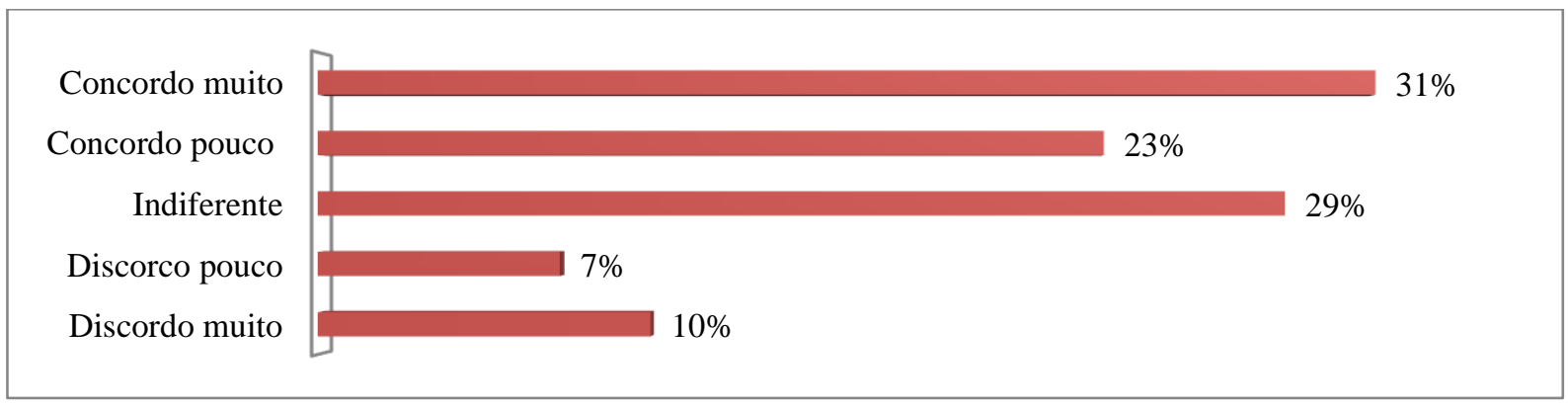

Figura 2 - Obrigatoriedade das declarações.

Fonte: dados da pesquisa. 
Os resultados obtidos a partir da Figura 2 evidenciam que 54\% dos entrevistados, ou seja, mais da metade, reconhecem a obrigatoriedade do envio das declarações acessórias para todas as pessoas jurídicas, sejam com finalidade lucrativa ou não, e todas estão sujeitas a multa caso não enviem a declaração no prazo estabelecido, inclusive as instituições do terceiro setor.

Para a questão 5, foi feita uma afirmativa a respeito da Lei $n^{\circ} 10.406 / 2012$, de que as fundações só poderão ser constituídas para fins religiosos, morais, culturais ou de assistência, e o instituidor deverá fazer dotação de bens mediante escritura pública ou testamento. Com essas respostas, foi encontrada uma média de 3,17 para a questão.

A partir dessas médias, tem-se um ranking médio da questão com um resultado não muito satisfatório, mantendo-se muito próximo à nota 3, caracterizando uma "indiferença" em relação ao assunto, remetendo a uma falta de conhecimento dos estudantes sobre a matéria relacionada à constituição das fundações.

Para a análise da questão 6 , foi levado em consideração o conhecimento dos respondentes sobre a legislação aplicável ao terceiro setor e sobre o reconhecimento e mensuração de doações, que devem ser avaliadas ao valor justo e contabilizadas como receitas. Já na questão 7 foi analisado o entendimento dos estudantes a respeito da realização dos testes de recuperabilidade para todos os bens do ativo imobilizado que a instituição tenha registrado em seu plano de contas.

As médias obtidas foram 3,28 e 3,91, respectivamente, representando um resultado considerado satisfatório, por ser maior que 3, contudo, verificou-se que existe algum grau de deficiência desses conhecimentos.

Na Figura 3 é apresentado o resultado para a questão 8, em que, para os entrevistados, a contabilidade atualizada é fonte de transparência na gestão dos recursos da entidade, por isso $68 \%$ deles concordam com a afirmativa e apenas $1 \%$ discorda totalmente do que lhes foi afirmado. Desta forma, é possível perceber que existe conhecimento deles sobre a importância da contabilidade, não apenas nas entidades do primeiro e do segundo setor, mas também nas entidades do terceiro setor, tanto para a prestação de contas como para uma melhor gestão da entidade. 
Percepção dos alunos de ciências contábeis sobre a prática da contabilidade aplicada ao terceiro setor

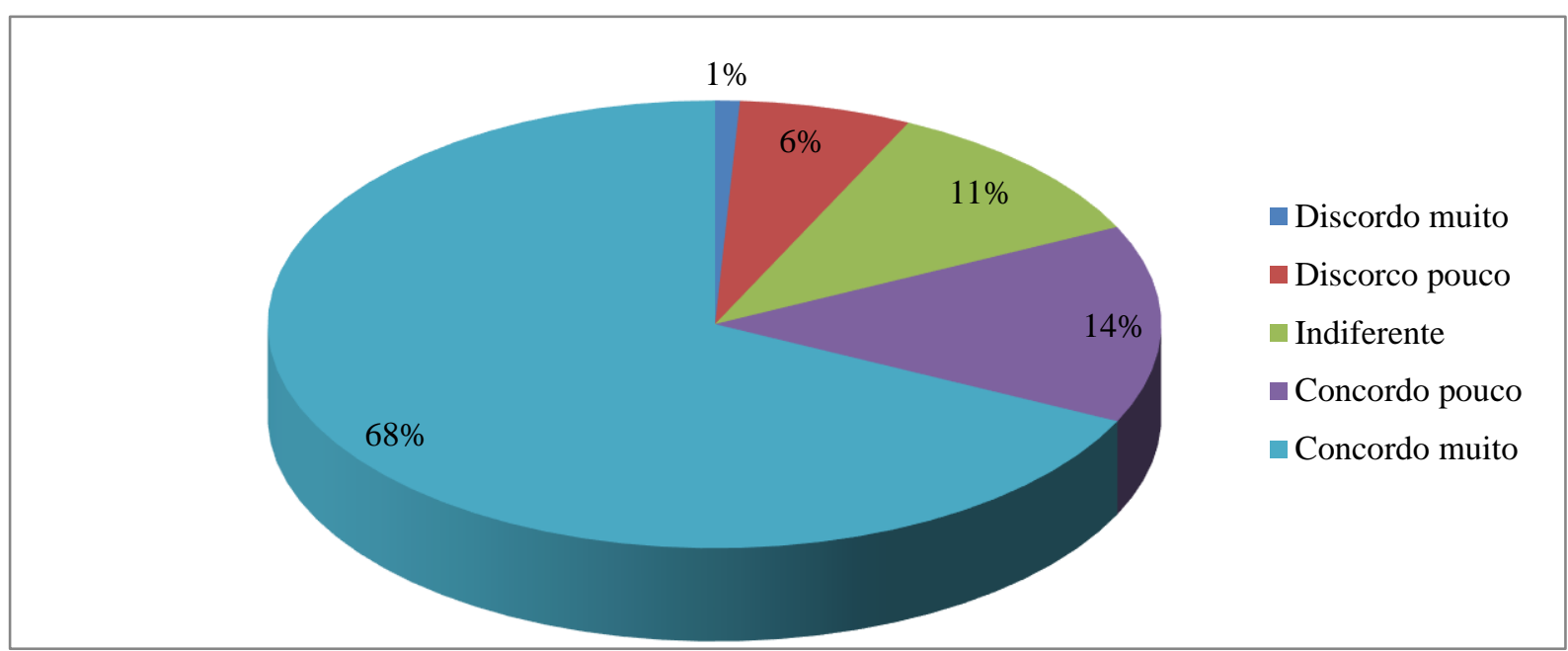

Figura 3 - Contabilidade atualizada para prestação de conta. Fonte: dados da pesquisa.

As entidades de interesse social devem prestar contas sobre os recursos recebidos e em que foram aplicados para a sociedade, e para isso precisam manter uma contabilidade sempre atualizada, como forma de transparência para seus financiadores.

As duas últimas questões trataram a respeito da auditoria para as instituições do terceiro setor (pergunta 9) e sobre o procedimento de transferência de patrimônio no caso de extinção das entidades (pergunta 10).

O ranking médio para a questão 9 foi 3,30, e para a 10 foi de 3,35, as respostas estão mais próximas a 5 do que de 1 . Desta forma, os entrevistados estão em concordância com as afirmativas, evidenciando que eles sabem da obrigatoriedade da auditoria independente para as instituições do terceiro setor como forma de se garantir a veracidade das informações por elas prestadas por meio dos relatórios contábeis. Contudo, também é um sinal de que não é um pensamento unânime, visto que isso só seria evidenciado se a média fosse 5 , em que todos deveriam concordar totalmente a respeito.

\section{CONSIDERAÇÕES FINAIS}

Este trabalho buscou verificar o nível de conhecimento dos alunos de ciências contábeis em relação às práticas contábeis adotadas pelas instituições do terceiro setor. Como forma de alcançar o objetivo do estudo, foi aplicado um questionário nas IES visando identificar a percepção dos alunos sobre o tema e os procedimentos contábeis aplicados nas entidades do terceiro setor. Os questionários foram enviados para seis IES de Natal e uma de Mossoró, sendo obtido um retorno de 112 respostas. 
Com relação à obrigatoriedade do ensino da disciplina nas IES pesquisadas, verificouse que, na maioria delas, a disciplina compõe o quadro das complementares, e quanto à percepção dos entrevistados sobre o tema em questão, verificou-se que os alunos conhecem pouco sobre o assunto, o que evidencia a falta de conhecimento deles sobre pontos específicos da contabilidade do terceiro setor, como a obrigatoriedade de divulgação das demonstrações contábeis, envio das declarações acessórias e contabilização das receitas com doações.

Quanto às normas contábeis aplicadas ao terceiro setor, foi verificado que os estudantes conhecem a obrigatoriedade das demonstrações contábeis a serem divulgadas pelas entidades ao final de cada exercício, bem como a importância de se manter uma contabilidade atualizada para a tomada de decisão e sobre a conceituação jurídica do terceiro setor, sendo esse resultado melhor evidenciado a partir da análise do ranking médio. Ainda falando de normas, foi evidenciado que a maioria dos entrevistados concorda com a afirmativa a respeito da obrigatoriedade das declarações acessórias para as entidades do terceiro setor.

Com relação às normas contábeis, abordou-se no questionário sobre a mensuração e contabilização das receitas com doações e realização do teste de recuperabilidade de ativos para os bens do ativo imobilizado e sobre a realização de auditoria nas demonstrações contábeis nas instituições. Com a análise do ranking médio das respostas, concluiu-se que os estudantes concordam com as afirmativas sobre a aplicação das normas contábeis para as instituições do terceiro setor.

Quanto à análise dos conceitos de terceiro setor, verificou-se que os estudantes conhecem e entendem a sua conceituação jurídica e sabem quais os procedimentos adotados para o caso de extinção de uma associação ou fundação, quanto à destinação de seu patrimônio, mas ao mesmo tempo desconhecem quais são as formas de constituição das fundações.

Portanto, conclui-se, no resultado da pesquisa, que os alunos de ciências contábeis das IES de Natal e Mossoró possuem apenas os conhecimentos básicos sobre o assunto, tais como conceitos. Mas em relação à aplicação da contabilidade no cotidiano das instituições do terceiro setor, ainda é pequeno o conhecimento. Com isso, é possível perceber que o ensino da contabilidade aplicada ao terceiro setor não condiz com a formação esperada para o estudante de acordo com o que sugere a Proposta Nacional de Conteúdo para o Curso de Graduação em Ciências Contábeis (FBC, 2009), principalmente no que compete à legislação contábil inerente a essas instituições.

Estes achados coincidem com a pesquisa de Rodrigues et al. (2016), em que os alunos percebiam a falta de uma integração com profissionais na área, possibilitando, assim, uma aplicação prática dos conhecimentos adquiridos. De certa forma se assemelha aos achados de 
Cavalcante et al. (2017), visto que a aplicação dos conceitos teóricos em termos práticos também foi uma das deficiências percebidas nos estudos envolvendo a contabilidade ambiental.

Como sugestão para futuras pesquisas, recomenda-se um estudo mais aprofundado sobre o ensino contabilidade com foco no terceiro setor nas demais instituições, para que sejam verificadas se elas estão ministrando a disciplina de acordo com a ementa proposta.

\section{REFERÊNCIAS}

ALVES, A. C.; TEIXEIRA, V. V. N.; OLIVEIRA, I. G. V. Percepção dos discentes do curso de graduação em administração em relação às disciplinas da área de contabilidade. Revista Administração em Diálogo, v. 19, n. 3, p. 24-48, 2017.

ANDRADE, M. M. Como preparar trabalhos para cursos de pós-graduação: noções práticas. 5. ed. São Paulo: Atlas, 2002.

BEUREN, I. M.; LONGARAY, A. A.; RAUPP, F. M.; SOUSA, M. A. B. Como elaborar trabalhos monográficos em contabilidade: teoria e prática. 3. ed. São Paulo: Atlas, 2012.

BOSSARD II, L. C. H. Terceiro setor: uma realidade, uma esperança. Abracicon Saber, v. 3, p.14-16, 2013.

BRASIL. Ministério da Educação. Conselho Nacional de Educação. Câmara de Educação Superior. Resolução CNE/CES nº 10, de 16 de dezembro de 2004. Institui as Diretrizes Curriculares Nacionais para o Curso de Graduação em Ciências Contábeis, bacharelado, e dá outras providências. Diário Oficial da União, Brasília, DF, 28 dez. 2004.

Ministério do Planejamento, Orçamento e Gestão. Instituto Brasileiro de Geografia e Estatística. As fundações privadas e associações sem fins lucrativos no Brasil 2010. Rio de Janeiro, 2012. (Estudos e Pesquisas Informação Econômica, 20). Disponível em: <ftp://ftp.ibge.gov.br/Fundacoes_Privadas_e_Associacoes/2010/fasfil.pdf $>$. Acesso em: 25 ago. 2018.

CAVAlCANTE, G. M.; ISRAEL, S. M. B.; AQUINO, M. M. F.; CEOLIN, A. C. Contabilidade ambiental: um estudo sobre a percepção dos estudantes de graduação em ciências contábeis da cidade de Maceió (AL). Revista Mineira de Contabilidade, v. 18, n. 3, p. 40-51, 2017.

COELHO, S. C. T. Terceiro setor: um estudo comparado entre Brasil e Estados Unidos. São Paulo: Senac São Paulo, 2000.

COMITÊ DE PRONUNCIAMENTOS CONTÁBEIS. Pronunciamento Técnico CPC 07 (R1): subvenção e assistência governamentais. Brasília, 2 dez. 2010. Disponível em: <http://www.cpc.org.br/CPC/Documentos-Emitidos/Pronunciamentos/Pronunciamento?Id= 38>. Acesso em: 2 abr. 2014.

FUNDAÇÃO BRASILEIRA DE CONTABILIDADE. Caderno de procedimentos aplicáveis a prestação de contas das entidades do terceiro setor (fundações). 2. ed. 
Brasília, 2012. Disponível em: <http://portalcfc.org.br/wordpress/wp-content/uploads/2013/ 01/miolo_terceiro_setor_2012_web.pdf>. Acesso em: 25 ago. 2018.

\section{Proposta Nacional de Conteúdo para o Curso de Graduação em Ciências}

Contábeis. 2. ed. Brasília, 2009. Disponível em: <http://portalcfc.org.br/wordpress/wpcontent/uploads/2013/01/proposta.pdf >. Acesso em: 25 ago. 2018.

FAGUNDES, J. A.; BUTNER, L. B.; STURM, G. A.; MACIEL, N. P. Formalização contábil em entidade de assistência social: um estudo de caso sob a ótica da gestão de custos.

Contexto, v. 12, n. 21, p. 59-67, 2012.

FALCONER, A. P. A promessa do terceiro setor: um estudo sobre a construção do papel das organizações sem fins lucrativos e do seu campo de gestão. 1999. Dissertação (Mestrado em Administração) - Faculdade de Economia, Administração e Contabilidade da Universidade de São Paulo, São Paulo, 1999.

GIL, A. C. Métodos e técnicas de pesquisa social. 6. ed. São Paulo: Atlas, 2008.

IUDÍCIBUS, S. Teoria da contabilidade. 4. ed. São Paulo: Atlas: 2010.

MARCONI, M. A.; LAKATOS, E. M. Técnicas de pesquisa: planejamento e execução de pesquisas, amostragens e técnicas de pesquisa, elaboração, análise e interpretação de dados. 7 . ed. São Paulo: Atlas, 2010.

MARION, J. C. Contabilidade básica. 10. ed. São Paulo: Atlas, 2009.

MEREGE, L. C. Terceiro setor: finalmente no PIB. Revista Integração, CETS FGV-EAESP, abr. 2007. Disponível em: <http://www.ipea.gov.br/acaosocial/article926d.html?id_article= 388>. Acesso em: 4 abr. 2014.

NIYAMA, J. K.; SILVA, C. A. T. Teoria da contabilidade. São Paulo: Atlas, 2011.

OLAK, P. A.; NASCIMENTO, D. T. Contabilidade para entidades sem fins lucrativos: terceiro setor. 3. ed. São Paulo: Atlas, 2010.

OLAK, P. A.; SLOMSKI, V.; ALVES, C. V. O. As publicações acadêmicas da pesquisa contábil no Brasil, no âmbito das organizações do terceiro setor. Revista de Educação e Pesquisa em Contabilidade, v. 2, n. 1, p.24-46, 2008.

PAES, J. E. S. Fundações e entidades de interesse social: aspectos jurídicos, administrativos, contábeis e tributários. 4. ed. Brasília: Brasília Jurídica, 2003.

RODRIGUES, A. C.; MOREIRA, F. S.; FIRMINO, J. E.; SILVA, M. C. A percepção dos alunos do curso de ciências contábeis acerca do ensino e do mercado de trabalho em perícia contábil. Revista Capital Científico, v. 14, n. 2, p. 1-15, 2016.

RICHARDSON, R. J. Pesquisa social: métodos e técnicas. 3. ed. São Paulo: Atlas, 1999.

ROSA, A. M. Marco legal do terceiro setor: aspectos teóricos e práticos. Florianópolis: TJSC, 2003. 